Volume 9, No.4, July - August 2020

International Journal of Advanced Trends in Computer Science and Engineering

Available Online at http://www.warse.org/IJATCSE/static/pdf/file/ijatcse274942020.pdf

https://doi.org/10.30534/ijatcse/2020/274942020

\title{
Application of Artificial Neural Networks for Predicting the Stock Price in Law
}

\author{
Sergey G. Eremin ${ }^{1}$, Alexander M. Belyaev ${ }^{2}$, Sergey G. Kamolov ${ }^{3}$, Anna A. Kopina ${ }^{4}$, Alexey M. Evsikov ${ }^{5}$ \\ ${ }^{1}$ Federal state educational budgetary institution of higher education "Financial University under the Government \\ of the Russian Federation", Russia, SGEremin@fa.ru \\ ${ }^{2}$ Federal state educational budgetary institution of higher education "Financial University under the Government \\ of the Russian Federation", Russia, ABelyaev@ fa.ru \\ ${ }^{3}$ Federal state Autonomous educational institution of higher education " Moscow state Institute of international \\ relations (University) Ministry of foreign Affairs of the Russian Federation", Russia, skamolov@ yahoo.com \\ ${ }^{4}$ Institute of legislation and comparative law under the Government of the Russian Federation, Russia, \\ a.kopina@yandex.ru \\ ${ }^{5}$ Federal state budgetary educational institution of higher education "Russian state University of justice", Russia, \\ ameevsikov@gmail.com
}

\begin{abstract}
The paper considers the problem of forecasting the company's share price in the conditions of playing on the stock exchange using artificial neural networks. An artificial neural network of direct propagation is used. The method of reverse error propagation is selected for the training method. A wide range of experiments was conducted on a set of data that covers the summer period of stock market trading. This makes it possible to analyze and compare the effectiveness of various artificial neural network designs using various activation functions. Artificial neural networks have been used in the last decade to solve problems of image classification, clustering /classification, function approximation function, prediction / forecasting / forecasting, optimization, content addressable memory and control.
\end{abstract}

Key words : Artificial neural network, forecasting methods, artificial intelligence.

\section{INTRODUCTION}

For a specific task, an ins designed and taught its adequate solution [4]. The experience gained in the process of solving a wide range of practical problems, in the case of ins application, consists in choosing the topology of the neural network, the training algorithm, the activation functions of neurons, and a number of numerical parameters for each practical problem [1-3]. The following results are devoted to the solution of these problems in the case of building a neural network for predicting the share price of a certain company on the stock exchange [5].

Let's assume that for each stock that is sold on the exchange, the price at the time of opening the exchange, at the time of closing it, and the highest price during the working day for each of the days for a certain period is known. The task of forecasting is to find the maximum price of a stock on any given day with already known values of stock prices at the time of opening and closing of the exchange [6].

To solve this problem, several ins were constructed and studied, which are represented by a weighted oriented graph in Fig. 1. the Vertices of the graph are neurons of the network, and the edges correspond to connections between neurons. Weights that are the desired parameters of the neural network form a vector [7-9]. The considered neural networks are neural networks of direct signal propagation. The input values for each ins are-the share price at the time of opening of the exchange, and-the share price at the time of closing of the exchange on the day.

\section{MATERIALS AND METHODS}

Using a neural network to solve a forecasting problem consists of two stages: the stage of training a neural network on a training set, and the stage of calculating the predicted value for arbitrary input parameter values by the trained network. For the purpose of training the considered ins, a class of error correction methods was used, namely, the method of back propagation of the error, which relates to training with a teacher. Learning with a teacher involves the existence of multiple learning pairs of input and output [10]. In our case, the input is $\left(x_{1}(t), x_{2}(t)\right)$, and the output is $d(t)$, the previously known value of the highest share price. To train the ins and test its ability to predict $[1, T]\left[t^{1}, t^{2}\right], 1<t^{1}<t^{2}<$ $T$ and $\left[t^{3}, t^{4}\right], 1<t^{3}<t^{4}<T$. We will train ins on one of the platforms, and check the quality of forecasting on the other. Hence, the elements of the training set are pairs $\left\langle\left(x_{1}(t), x_{2}(t)\right), d(t)\right\rangle t \in\left[t^{1}, t^{2}\right]$. 

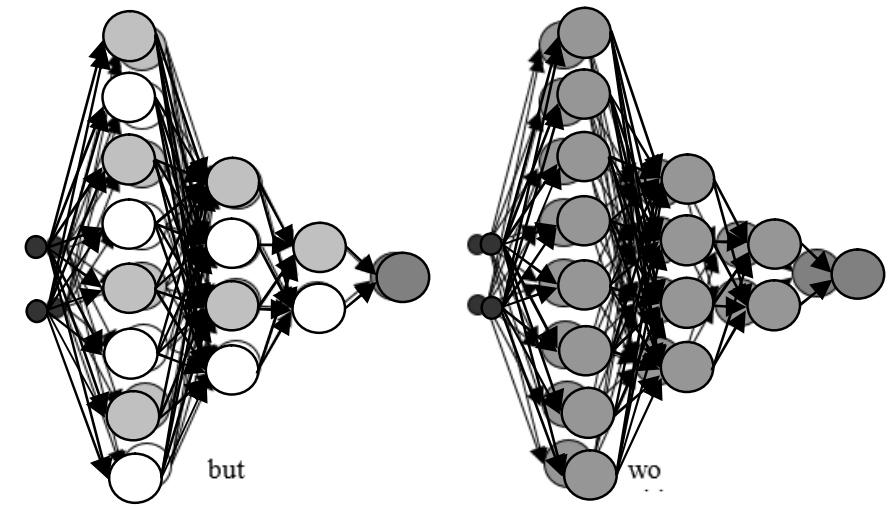

Figure 1: Activation functions $f_{2}(x), f_{3}(x)$, which alternate in layer (a) and activate the function of neurons $f_{1}(x)(\mathrm{b})$.

Figure 1 shows us activation functions in neural network. For the activation functions of neurons of the inner layers of the proposed ins, the following functions were selected. Classical literature on the theory of ins $[2,3]$ recommends choosing sigmoids for the activation functions of neurons, for example, $f_{1}(x)$. The main attraction of these functions lies in their limitations, and therefore it is interesting to use other limited functions, for example $f_{2}(x), f_{3}(x)$.

The input value for activation functions is the weighted sum of values that are transmitted to the neuron by connections from the previous layer, i.e. $f\left(s_{j}^{k}\right)=f\left(\sum_{i} w_{\mathrm{ij}}^{k} x_{\mathrm{ij}}^{k}\right)$, where $j$ is the index of the neuron for which the activation function is calculated; $k$ is the number of the layer to which the neuron $j$ belongs; $i$ is the index of summation, which is performed on all connections that lead from neurons in the interval $(k-1)$ to neuron $j$.

The neuron in the output layer calculates the value $y=$ $\sum_{i} w_{\mathrm{ij}}^{\text {last }} x_{\mathrm{ij}}^{\text {last }}$, i.e. the weighted sum, which is the output of the ins [11-13].

Training using error correction involves minimizing the error function $E(w, t)=\frac{1}{2} \sum_{t}(y(t)-d(t))^{2}$. In other words, it is necessary to minimize the square deviation of the ins outputs from the previously known ETH-level values. Minimizing the error function using one of the well-known optimization methods is not possible due to the dimensionality of the problem. The method of back propagation of the error solves the problem of dimensionality [2] and provides the following calculations [14].

We can calculate the new weight values using the formula

$w_{\mathrm{ij}}^{k}(n)=w_{\mathrm{ij}}^{k}(n-1)+W_{\mathrm{ij}}^{k}$,

where $n$ is the number of the training step. The value of $\Delta w_{\mathrm{ij}}^{k}$ for the source layer is calculated differently than for the rest. Namely:

$W_{\mathrm{ij}}^{\text {last }}=\alpha \delta_{j}^{\text {last }} f_{i}^{\text {last-1, }}$,

where

$\delta_{j}^{\text {last }}=\frac{\mathrm{df}_{j}^{\text {last }}}{\mathrm{ds}_{j}^{\text {last }}}\left(y_{j}-d_{j}\right)$.

Index $j=1$, because the output layer in the proposed ins contains a single neuron [15].

For the remaining segments

$W_{\mathrm{ij}}^{k}=\alpha \delta_{j}^{k} f_{i}^{k-1}$,

where $\delta_{j}^{k}=\frac{\mathrm{dl}_{j}^{k}}{\mathrm{ds}_{j}^{k}} \sum_{l} \delta_{l}^{k+1} w_{\mathrm{j} 1}^{k+1}$,

and the lindex corresponds to the numbers of neurons in the layer $(k+1)$ with which the link neuron $j$ has a connection.

The value is a learning step. Note that there is no effective method for selecting the training step, so this value is usually selected before the start of training and is not changed. The convergence condition of the reverse propagation method is given by the error value $E(w, t) \leq \varepsilon$, where $\varepsilon$ is chosen according to the conditions of a particular problem [16-19].

Let's describe the reverse propagation learning algorithm. Let the training set contain $N$ elements.

Initialization. We will take the counter of training pairs that have already taken part in training as zero, i.e. count $=0$. Choose the acceptable accuracy of the total squared deviations of the outputs of the Ann for all the training set, i.e. the value $\varepsilon$; and acceptable accuracy deviation specific yield of ins from the appropriate benchmark, i.e., $\varepsilon_{1}$.

\section{Main loop.}

Step 1. The calculated value of $E(w, t)=\frac{1}{2} \sum_{t}(y(t)-$ $d(t))^{2}$. If

$E(w, t) \leq \varepsilon$, then end: the ins outputs are valid. If $E(w, t)>$ $>\varepsilon$, then proceed to step 2 .

Step 2. If count $<N$, then go to step 3, otherwise go to step 1 Step 3. Randomly selecting the training pair $\left\langle\left(x_{1}(t), x_{2}(t)\right), d(t)\right\rangle$ from the training set and calculate the output $y(t)$ Ins for input values $\left(x_{1}(t), x_{2}(t)\right)$. We accept count $=$ count +1 .

Step 4. Calculating the value $A=|y(t)-d(t)|$.

Step 5. If $A>>\varepsilon_{1}$, then we perform the training according to formulas (1) - (5), otherwise we return to step 2.

Table 1: Results of training offered by ins on various training sets by training step 0,1

\begin{tabular}{|c|c|c|c|c|c|}
\hline No. & ins & $\begin{array}{l}\text { the scale } \\
\text { Factors }\end{array}$ & $\begin{array}{l}\text { Training } \\
\text { period }\end{array}$ & $\begin{array}{l}\text { The } \\
\text { accuracy } \\
\text { of the } \\
\text { OBU } \\
\text { niya }\end{array}$ & $\begin{array}{l}\text { Number } \\
\text { of } \\
\text { iterations }\end{array}$ \\
\hline 1 & \multirow[t]{2}{*}{$\mathrm{b}$} & Non-scale. & \multirow[t]{4}{*}[0,100]{} & 0,00872 & 3000 \\
\hline 2 & & 6 & & 0,00853 & 3000 \\
\hline 3 & \multirow[t]{2}{*}{$\mathrm{a}$} & Non-scale. & & 0,008422 & 1600 \\
\hline 4 & & 6 & & 0,005122 & 1400 \\
\hline 5 & \multirow[t]{2}{*}{$\mathrm{b}$} & Non-scale. & \multirow[t]{4}{*}[0,500]{} & 0,023696 & 1000 \\
\hline 6 & & 4 & & 0,033471 & 1000 \\
\hline 7 & \multirow[t]{2}{*}{$\mathrm{a}$} & Non-scale. & & 0,02346 & 1000 \\
\hline 8 & & 4 & & 0,01285 & 1000 \\
\hline
\end{tabular}

For the study of ins as a forecasting technology, several of their constructions are considered. The ins used to get the results shown below are shown in Fig. 1. Training of the proposed ins was conducted on several training sets that have different statistical characteristics (mathematical expectation and variance). The prediction quality was also tested on several sets with different statistical characteristics. The results of training and forecasting are shown in tables 1,2 . the Accuracy of training in table 1 is reflected for such numbers of iterations as were acceptable for runtime [20]. Statistical 
characteristics of training sets and sets that were used to test the quality of forecasting are shown in table 3.

Table 2: Prediction results for the proposed ins on various prediction sets

\begin{tabular}{|c|c|c|c|}
\hline № & $\begin{array}{l}\text { Ins } \\
\text { number }\end{array}$ & $\begin{array}{l}\text { The period of } \\
\text { forecasting }\end{array}$ & Prediction accuracy \\
\hline 1 & \multirow[t]{2}{*}{$\mathrm{b}$} & \multirow[t]{4}{*}[100,200]{} & 0.00256 \\
\hline 2 & & & 0.00322 \\
\hline 3 & \multirow[t]{2}{*}{$\mathrm{a}$} & & 0.00116 \\
\hline 4 & & & 0.01095 \\
\hline 5 & \multirow[t]{2}{*}{$\mathrm{b}$} & \multirow[t]{4}{*}[500,600]{} & 0.005112 \\
\hline 6 & & & 0.007092 \\
\hline 7 & \multirow[t]{2}{*}{$\mathrm{a}$} & & 0.004729 \\
\hline 8 & & & 0.003462 \\
\hline
\end{tabular}

Table 3:Statistical characteristics of the set and the prediction set

\begin{tabular}{|l|l|l|l|l|l|l|l|l|}
\hline \multirow{2}{*}{ Feature } & \multicolumn{4}{|l|}{ Training program } & \multicolumn{4}{|c|}{ Set of forecasts } \\
\cline { 2 - 9 } & \multicolumn{2}{|c|}{$[0,100]$} & \multicolumn{2}{|c|}{$[0,500]$} & \multicolumn{2}{l|}{$[100,200]$} & \multicolumn{2}{l|}{$[500,600]$} \\
\hline & $x_{1}(t)$ & $x_{2}(t)$ & $x_{1}(t)$ & $x_{2}(t)$ & $x_{1}(t)$ & $x_{2}(t)$ & $x_{1}(t)$ & $x_{2}(t)$ \\
\hline $\begin{array}{l}\text { Varian } \\
\text { ce }\end{array}$ & $\begin{array}{l}0.19 \\
88\end{array}$ & $\begin{array}{l}0.20 \\
94\end{array}$ & $\begin{array}{l}0.13 \\
16\end{array}$ & $\begin{array}{l}0.13 \\
74\end{array}$ & $\begin{array}{l}0.013 \\
8\end{array}$ & $\begin{array}{l}0.01 \\
34\end{array}$ & $\begin{array}{l}0.0 \\
896\end{array}$ & $\begin{array}{l}0.8 \\
973\end{array}$ \\
\hline $\begin{array}{l}\text { Mathe } \\
\text { matical } \\
\text { expect } \\
\text { ation }\end{array}$ & $\begin{array}{l}0.41 \\
79\end{array}$ & $\begin{array}{l}0.42 \\
8\end{array}$ & $\begin{array}{l}0.23 \\
32\end{array}$ & $\begin{array}{l}0.23 \\
58\end{array}$ & $\begin{array}{l}0.210 \\
8\end{array}$ & $\begin{array}{l}0.21 \\
13\end{array}$ & $\begin{array}{l}0.2 \\
713\end{array}$ & $\begin{array}{l}0.2 \\
712\end{array}$ \\
\hline Max & 1.15 & 1.2 & 1.15 & 1.2 & 0.24 & $\begin{array}{l}0.24 \\
4\end{array}$ & $\begin{array}{l}0.4 \\
8\end{array}$ & $\begin{array}{l}0.4 \\
8\end{array}$ \\
\hline Min & 0.21 & 0.21 & 0.08 & 0.09 & 0.18 & 0.18 & $\begin{array}{l}0.1 \\
5\end{array}$ & $\begin{array}{l}0.1 \\
5\end{array}$ \\
\hline
\end{tabular}

During the training of ins (table 2,3), its paralysis may occur, that is, its inability to further learn. This may be due to the following reasons [21]:

the mathematical expectations of input values are high, and their variance is small;

the mathematical expectations of input values are low, and the variance is small:

In the first case, there may be a situation when there is not enough bit depth of the computer to image the ins output; in the second case, we may get an indefinite learning time. To avoid paralysis in these cases, we suggest scaling the input values of the ins [2]. The results of training and forecasting with and without scaling are shown in table. 1. for these examples, scaling was performed according to the formula $i=1,2$, where-the input values are scaled, $M_{i}=$ $\frac{1}{N} \sum_{t=t^{1}}^{t^{2}} x_{i}(t) \quad-$ mathematical expectations of input parameters, $N-$ power in the interval $\left[t^{1}, t^{2}\right], c-$ zoom level. Tables 1 and 2 show the results of training and forecasting for both scale-based and non-scale input data [22].

The most successful described experiments are experiment \# 5 for the neural network shown in Figure 1, b, and experiment \#8 for the neural network shown in Figure 1,a. In Fig. 2-9 shows the results of training and prediction for these experiments; Figures 2 and 6 are the total square deviation of the network outputs from the reference values during training, respectively, for experiments \#5 and \#8; figures 3 and 7 depict curves that integrally characterize the learning process for experiments \#5 and \#8, respectively [23]. By comparing these results, it is easy to evaluate the convergence process of the training method for different ins. Note that in the case of using $\sin (x)$ and $\cos (x)$ for activation functions of neurons, the learning rate was higher, and the total quadratic deviation during prediction was less than at $\frac{1}{1+e^{-x}}$. Figures 4 and 8 show the absolute deviation of the ins outputs from the reference ones on the forecasting set for exponents \# 5 and \#8, respectively; Figures 6 and 9 contain graphs of real stock prices and their approximation by the proposed ins.

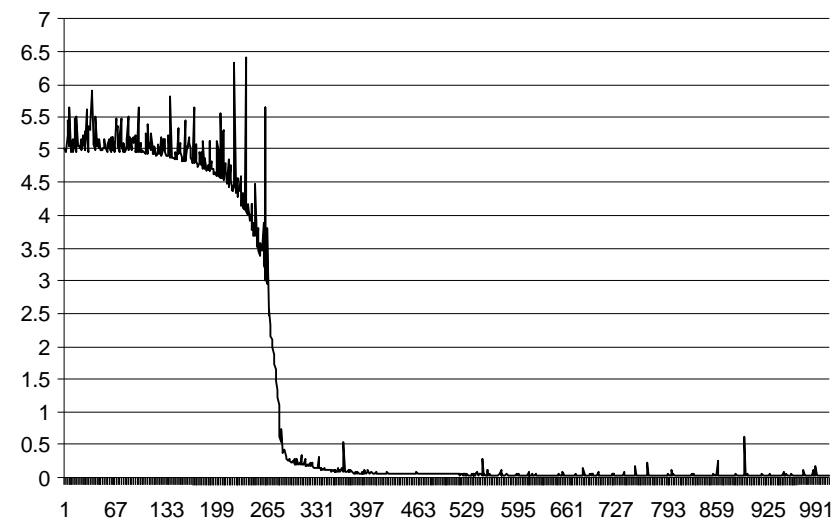

Figure 2: flow Chart of the learning process for experiment \# 5.

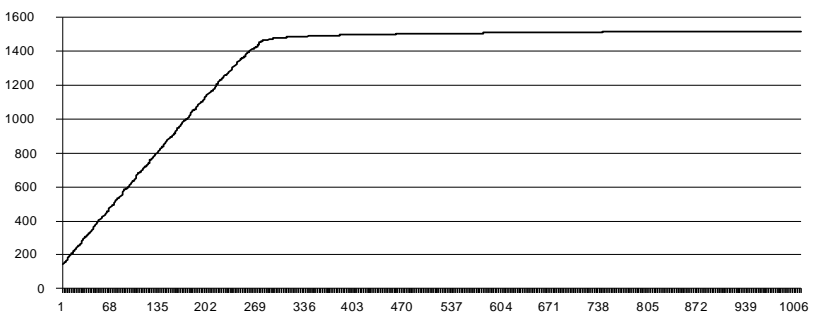

Figure 3: learning Curve for experiment \#5.

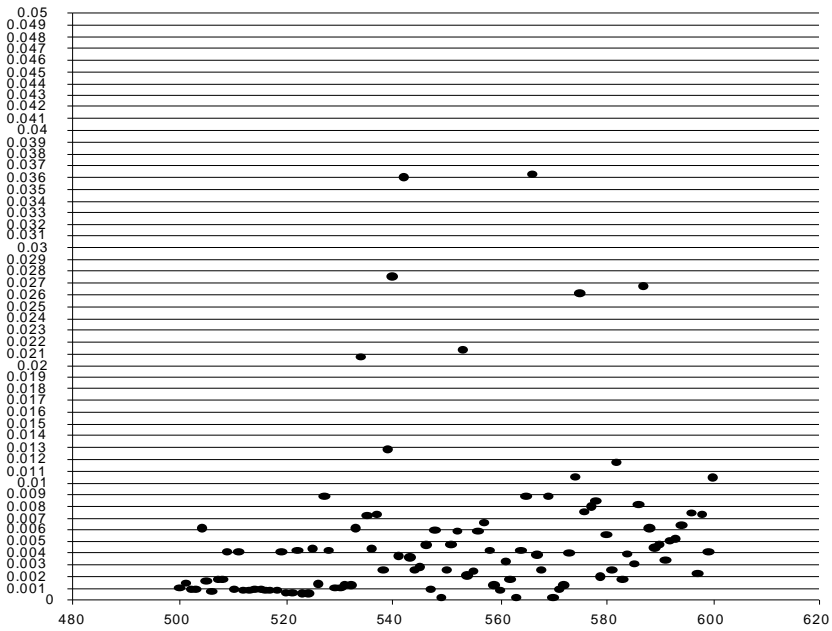

Figure 4: Values of absolute deviations of ins outputs from the standards on the prediction set for experiment \#5. 


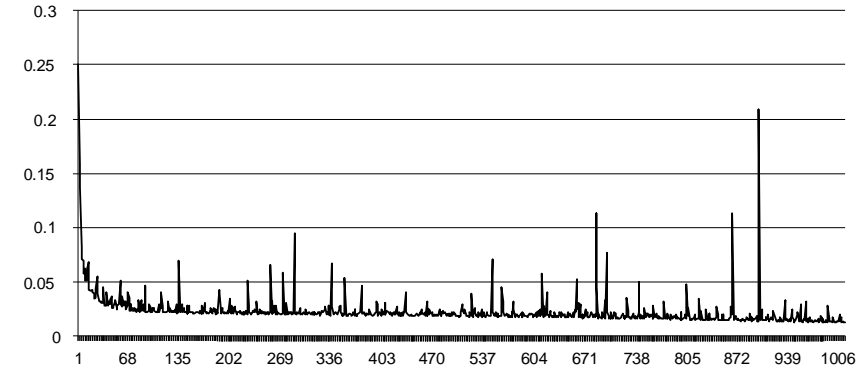

Figure 5: learning process Graph for experiment \# 8.

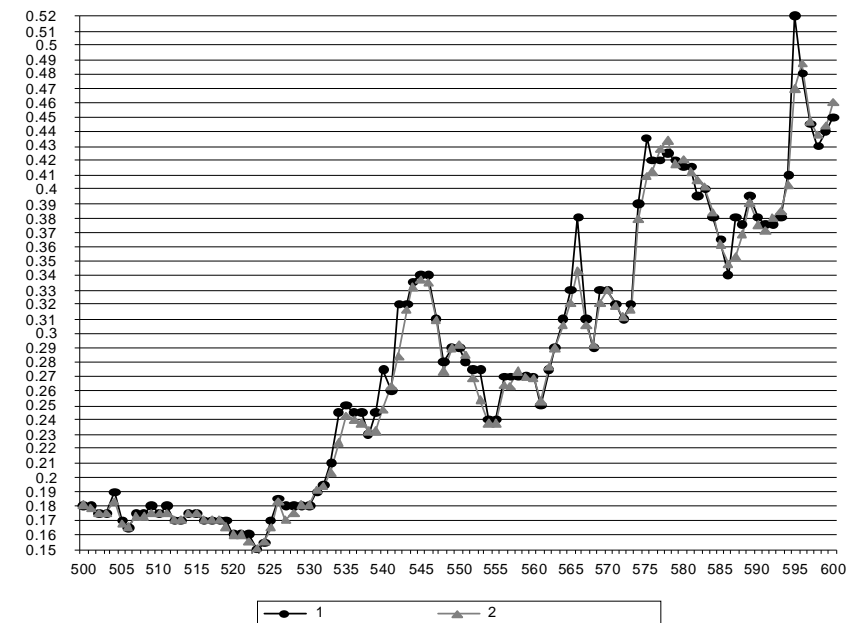

Figure 6: Chart of changes in the real (1) highest share price and forecast (2) prices for experiment \# 5.

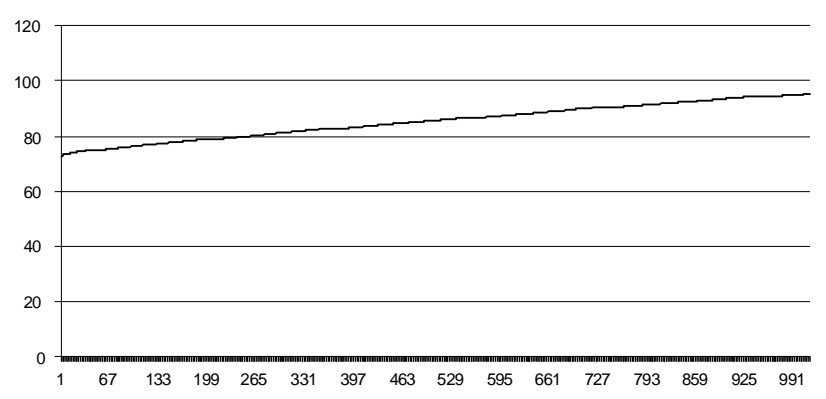

Figure 7: learning Curve for experiment \# 8.

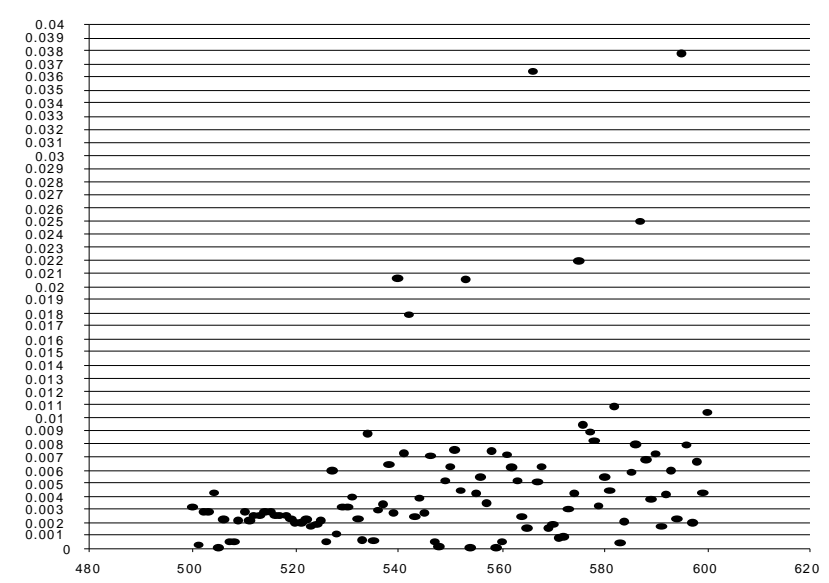

Figure 8: Value of absolute deviations of the ins outputs from the standards on the prediction set for experiment No. 8 .

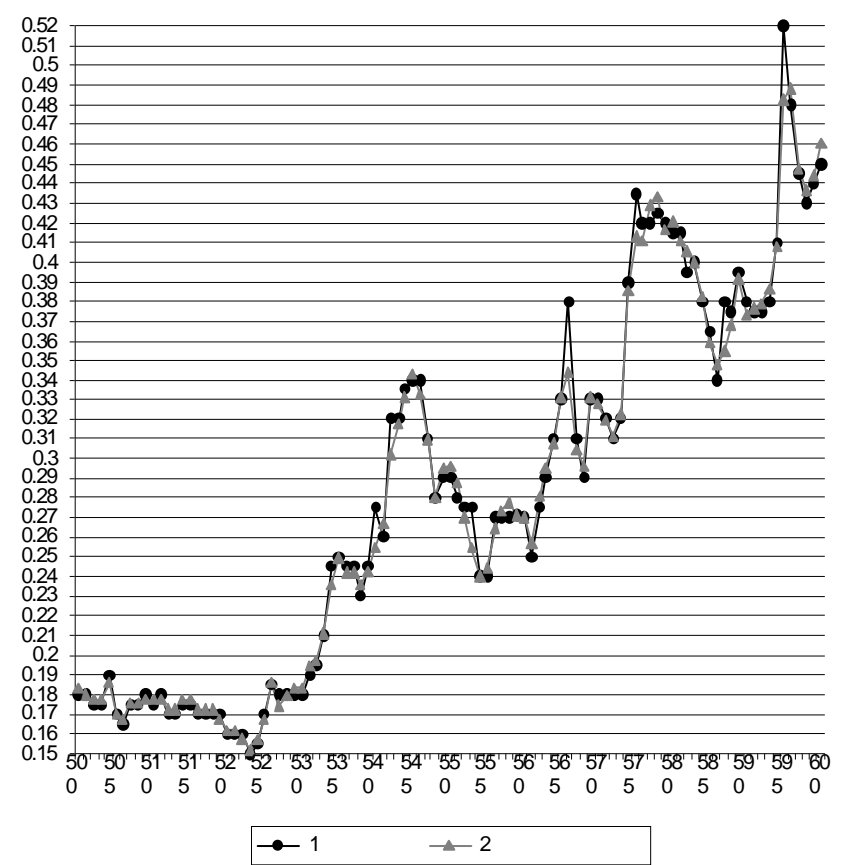

Figure 9: Chart of changes in the real (1) highest share price and forecast (2) prices for experiment \# 8.

Prediction has a significant impact on decision-making in business, science and engineering. Stock market prediction is a typical application of prediction technique [24].

Numerous advances have been made in developing intelligent systems, some inspired by biological neural networks. Researchers from many scientific disciplines are designing artificial neural networks (ANN) to solve a variety of problems in pattern recognition, prediction, optimization, associative memory, and control. ANNs provide existing alternatives, and many applications could benefit from using them.

\section{CONCLUSION}

Using a neural network to solve a forecasting problem consists of two stages: the stage of training a neural network on a training set, and the stage of calculating the predicted value for arbitrary input parameter values by the trained network. For the purpose of training the considered ins, a class of error correction methods was used, namely, the method of back propagation of the error, which relates to training with a teacher. Learning with a teacher involves the existence of multiple learning pairs of input and output. In our case, the input is $\left(x_{1}(t), x_{2}(t)\right)$, and the output is $d(t)$, the previously known value of the highest share price. To train the ins and test its ability to predict $\left[t^{1}, t^{2}\right], 1<t^{1}<t^{2}<T$ и $\left[t^{3}, t^{4}\right], 1<t^{3}<t^{4}<T$. We will train ins on one of the platforms, and check the quality of forecasting on the other. Hence, the elements of the training set are pairs $\left\langle\left(x_{1}(t), x_{2}(t)\right), d(t)\right\rangle t \in\left[t^{1}, t^{2}\right]$. 


\section{REFERENCES}

1. Artyukhin R.E. (2013) Drawing up, external verification, consideration and approval of budget reporting: scientific and practical commentary of section VIII.1 of the Budget Code of the Russian Federation. Reforms and law, 1, 2-11.

2. Rykova A.A. (2016) International commercial contracts as a means of self-regulation. Commercial Law, 1.

3. Rudryashov V.V. (2014) International financial standards as a concept for regulating international financial relations. Law and Economy, 1, 21-31.

4. Ponomaryova K.A. (2005) On the issue of "soft law" in the regulation of international private law relations. State and Law, 3.

5. Fundamental ISDA Principles for Effective Deposit Insurance Systems URL:

http://www.asv.org.ru/documents_analytik/analytics/inte rnational/332460/ (accessed on 31.10.2018).

6. Marochkin S.Yu., Khalafyan R.M. (2011) Principles of European Contract Law and Principles of European Law // Private International Law: in 2 volumes. V. 1: General Part. Moscow

7. Decree of the Finance Ministry of the Russian Federation dtd. 2 July 2010, No. 66n "On the forms of accounting reporting of organisations" // ConsultantPlus

8. Decree of the Finance Ministry of the Russian Federation dtd. November 25 2011, No. 160n "On the implementation of International Financial Reporting Standards and Explanations of International Financial Reporting Standards in the Russian Federation"// ConsultantPlus

9. Decree of the Finance Ministry of the Russian Federation dtd. December 28 2015, No. 217n "On the Introduction of International Financial Reporting Standards and Explanations of International Financial Reporting Standards in force in the territory of the Russian Federation and on recognizing invalid some orders (certain provisions of orders) of the Finance Ministry of the Russian Federation"

10. Principles for IOSCO financial market infrastructures (non-binding translation into Russian) URL:

https://www.google.ru/url?sa=t\&rct=j\&q=\&esrc=s\&sou rce=web\&cd=1\&ved=0ahUKEwjS (date of access: 31.10.2018).

11. Tunkin G.I. (2014) The theory of international law. M., Zercalo.

12. Fogelson Yu. B. (2014) Soft law and supremacy of law. Russian Law Journal, 11.

13. Aoki S. (2012) The Function of "Soft Law" in the Development of International Space Law // Soft Law in Outer Space. The Function of Non-binding Norms in International Space Law / I. Marboe (ed.). Vienna: Böhlau, 57-58.

14. Brünner Ch., Königsberger G. (2012) "Regulatory Impact Assessment" - A Tool to Strengthen Soft Law Regulations // Soft Law in Outer Space. The Function of
Non-binding Norms in International Space Law / I. Marboe (ed.). Vienna: Böhlau.

15. International Law: A Dictionary. (2015) Edited by B.A. Boczek. Lanham: Scarecrow Press.

16. Objectives and Principles of Securities Regulation URL:

https://www.iosco.org/library/pubdocs/pdf/IOSCOPD15 4.pdf (accessed on 31.10.2018).

17. Rodnyansky, D. V, Abramov, R. A., Repin, M. L., \& Nekrasova, E. A. (2019). Estimation of innovative clusters efficiency based on information management and basic models of data envelopment analysis. International Journal of Supply Chain Management, 8(5), 929-936.

18. Kolganova, I. S., \& Taran, S. S. (2019). Usage practicability of acer 1 . Species in landscaping in the central part of Rostov region. World Ecology Journal, 9(2), 95-105.

https://doi.org/10.25726/worldjournals.pro/WEJ.2019.2.5

19. Huzhahmetova, A. S. (2019). Analysis of the habitats of the genus Corylus $L$. proclamations and their seasonal patterns of fruiting. World Ecology Journal, 9(2), 106-118.

https://doi.org/10.25726/worldjournals.pro/WEJ.2019.2.

20. Burov A.G., Agüero D. Implementation of the Principles of Innovative Entrepreneurship in the Field. Academy of Entrepreneurship Journal. 2019. Vol. 25. Issue 1S. pp. 1-5.

21. Klyuev S.V., Bratanovskiy S.N., Trukhanov S.V., Manukyan H.A. Strengthening of concrete structures with composite based on carbon fiber // Journal of Computational and Theoretical Nanoscience. 2019. V.16. №7. P. 2810 - 2814. https://doi.org/10.1166/jctn.2019.8132

22. Tronin, S. A., Rodermel, T. A., Uspaeva, M. G., Shashkova, A. V, \& Calesci, M. (2019). Formation ofinnovative strategies of regional economic development. Space and Culture, India, 7(2), 65-75. https://doi.org/10.20896/saci.v7i2.457

23. Sunarya, P. A., Andriyani, F., Henderi, \& Rahardja, U. (2019). Algorithm automatic full time equivalent, case study of health service. International Journal of Advanced Trends in Computer Science and Engineering, 8(1.5 Special Issue), 387-391. https://doi.org/10.30534/ijatcse/2019/6281.52019

24. Sunil, G., Aluvala, S., Yamsani, N., Chythanya, K. R., \& Yalabaka, S. (2019). Security enhancement of genome sequence data in health care cloud. International Journal of Advanced Trends in Computer Science and Engineering, 8(2), 328-332.

https://doi.org/10.30534/ijatcse/2019/36822019 